\title{
A fast and conformal heating scheme for producing large thermal lesions using a 2D ultrasound phased array
}

\author{
HAO-LI LIU ${ }^{1,2}$, WIN-LI LIN ${ }^{3,4}$, \& YUNG-YAW CHEN ${ }^{5}$ \\ ${ }^{1}$ Department of Electrical Engineering, Chang-Gung University, Taoyuan, Taiwan, ${ }^{2}$ Molecular Imaging Centre, Chang- \\ Gung Memorial Hospital, Taoyuan, Taiwan, ${ }^{3}$ Institute of Biomedical Engineering, National Taiwan University, Taipei, \\ Taiwan, ${ }^{4}$ Division of Medical Engineering Research, National Health Research Institutes, Miaoli, Taiwan and \\ ${ }^{5}$ Department of Electrical Engineering, National Taiwan University, Taipei, Taiwan
}

(Received 22 August 2006; revised 8 September 2006; accepted 25 October 2006)

\begin{abstract}
The treatment conformability and the total treatment time of large tumors are both important issues in ultrasound thermal therapy. Previous heating strategies all show their restrictions in achieving these two issues to satisfactory levels simultaneously. This work theoretically presents a new heating strategy which is capable of both increasing the treatment conformability and shortening the treatment time, when using a $2 \mathrm{D}$ ultrasound phased array transducer. To perform this, a set of the multiple-foci patterns (considered the basic heating units) were temporally switched to steer the beam at different focal planes with the lesion length being well-controlled. Then, to conformally cover an irregular target volume, the 2D phased array was laterally shifted by a positioning system to deposit a suitable heating unit to cover a subvolume part. Results demonstrated that the totally treatment time can be largely reduced. The heating rate can be increased up to $0.96 \mathrm{~cm}^{3} / \mathrm{min}$ compared to the previously reported $0.26 \mathrm{~cm}^{3} / \mathrm{min}$. Also, the proposed scheme showed that the tumor regions can be completely treated with the normal tissue damage at satisfactory level. The feasibility of the proposed strategy for irregular tumor treatment was also demonstrated. This study offers useful information in large tumor treatment in ultrasound thermal therapy.
\end{abstract}

Keywords: Ultrasound thermal therapy, 2D ultrasound phased array, conformability, treatment time reduction, treatment planning

\section{Introduction}

Recent clinical studies showed that the ultrasound thermal therapy is a feasible treatment modality to extracorporeally and noninvasively treat larger tumors [1, 2]. Tempany et al. and Elizabeth et al. $[3,4]$ demonstrated that under the guidance of magnetic resonance imaging (MRI), the focused ultrasonic energy can be precisely steered into abdominal regions to thermally ablate uterine fibroids. Moreover, the same treatment modality was also applied to treat breast fibroadenomas $[5,6]$. Among the different tumor types, the uterine fibroids and the breast fibroadenomas were relatively large when comparing with the size of the focus (for example, in $1 \mathrm{MHz}$, the $-3 \mathrm{db}$ dimension of ultrasonic intensity is about $2-3 \mathrm{~mm}$ along the radial direction and $10-15 \mathrm{~mm}$ along the axial direction) [7]. Once the focal energy is employed to form overlapped thermally ablated volume to conform the targeting volume, numerous sonications would then be necessary. This implies that total used treatment time as well as the treatment conformability should be both considered as important factors to evaluate treatment quality.

There are two basic schemes that have been proposed in large-tumor treatments. The first scheme involves heating the tumor by consecutively steering a highly concentrated focus to cover the entire tumor accompanying with cooling intermissions between sonications been added [8, 9]. 
The amount of cooling intermission period was selected based on how well the apparent lesion extension toward skin can be prevented, or so-called "near-field" heating problem [8]. However, the major disadvantage of this approach is that the total treatment time can be prolonged to several hours due to the numerous cooling intermission time [8]. The second method was to employ a $2 \mathrm{D}$ phased array to steer multiple foci simultaneously. The advantage of this scheme was its capability to generate a relatively larger thermal lesion within one sonication, leading to fewer cooling intermissions to be used, and hence have potential to reduce the total treatment time. However, due to that the individual focus of the multiple focal pattern were less concentrated than a single focal one, longer exposure times were sometimes necessary to reach therapeutic temperature level, and this led to the tendency of thermal lesion extending toward skin due to its apparent side lobes than single focal patterns [8, 10-12]. Another disadvantage is that the shape of the generated lesions can be irregular and difficult to control, thus increasing the complexity of covering the tumors without damaging the surrounding normal tissue [13]. Neither of these two methods was satisfactory on the both requirements on treatment conformability and treatment time.

Recently, the technology by combining the focal pattern scanning becomes another potential scheme to solve large-tumor thermal ablation problem. Daum and Hynynen first demonstrated that by using the spherical phased array, a number of multiple focal patterns were formed and temporally switched during a short sonication period $(20 \mathrm{~s})$ to successfully create a large thermal lesion $\left(12 \times 12 \mathrm{~mm}^{2}\right.$ of cross-sectional area) [14]. On the other hand, Mougenot et al. [15] demonstrated that by mechanically scanning single focal pattern with a multi-spiral trajectory was also capable of producing large thermal lesion with the cross sectional diameter ranging $9-19 \mathrm{~mm}$. Malinen et al. [16] in their theoretical study also showed that by scanning the focal beam pattern was capable of producing 3D sphere-shaped thermal lesion ( $20 \mathrm{~mm}$ in diameter) in breast model. The aforementioned studies supported that scanning type technique is a useful and effective strategy for large tumor treatment and possibly achieve the requirement to reach satisfactory treatment conformability and treatment time.

In order to both reduce the total treatment time and improve the treatment conformability in one system, we have proposed a potential heating strategy by combining multiple focal-depth electronic scanning and mechanical lateral movement in a simplified convergent/divergent theoretical model with idealized energy deposition [17]. In this strategy, numbers of idealized power depositions at different focal depths were used to alternatively scan the entire target region, rather than steering the acoustic power deposition at single focal depth. This can effectively enlarge the single-exposure thermal lesion dimension along the axial direction, and is also advantageous in achieving a more uniformly distributed energy depositions within the sonication region. The shape of the induced lesions, therefore, became more regular and easier to be controlled than that of single focal-depth scanning. Moreover, when using this generated lesion to cover a larger volume, single lesion produced by multiple-focal depth scanning served as a single heating unit to treat a subvolume, and the transducer can be laterally shifted to heat different subregions sequentially to provide conformity over the entire region. This makes the generated thermal lesions fit the target regions well, and at the same time offers a short treatment time. To justify the applicability of this scheme in practical heating system, more realistic considerations, including practical wave propagation and nonlinear thermal property changes, are necessary. This work served as an extension of our former investigations, and to build up a standard procedure to apply this heating strategy into a practical $2 \mathrm{D}$ ultrasound thermal therapy system. Also in this article we show in detail how to implement this strategy in a $2 \mathrm{D}$ ultrasound phased array system to treat large tumors, and also how to investigate important factors of this heating strategy.

\section{Methods}

Heating procedure for large tumors using $2 D$ ultrasound phased array

Figure 1(a) is a schematic diagram showing the use of a $2 \mathrm{D}$ ultrasound phased array to treat large tumors. The $2 \mathrm{D}$ phased array contains 256 elements, and the arc length, curvature radius and driving frequency were $12,10 \mathrm{~cm}$, and $1.1 \mathrm{MHz}$, respectively, which was based on the design in Daum and Hynynen [14, 18]. The array configuration was chosen in this study due to its ability to create multiple focal patterns and focus shifting along transducer axis (at least $4 \mathrm{~cm}$ ) desired focal distance, and the large-scale aperture design can provide high geometric gain to treat deep-seated soft tissues such as abdomen or breast. The distance between the phased array and the skin was set to be $4 \mathrm{~cm}$. In heating large tumors, which cannot be covered by a single exposure, the overall target volume was first divided into several subvolumes. Then, each subvolume was heated sequentially by laterally shifting the phased array using a positioning system. Also when heating a subvolume, multiple focal-depth scanning scheme was used, and the focal-depth 


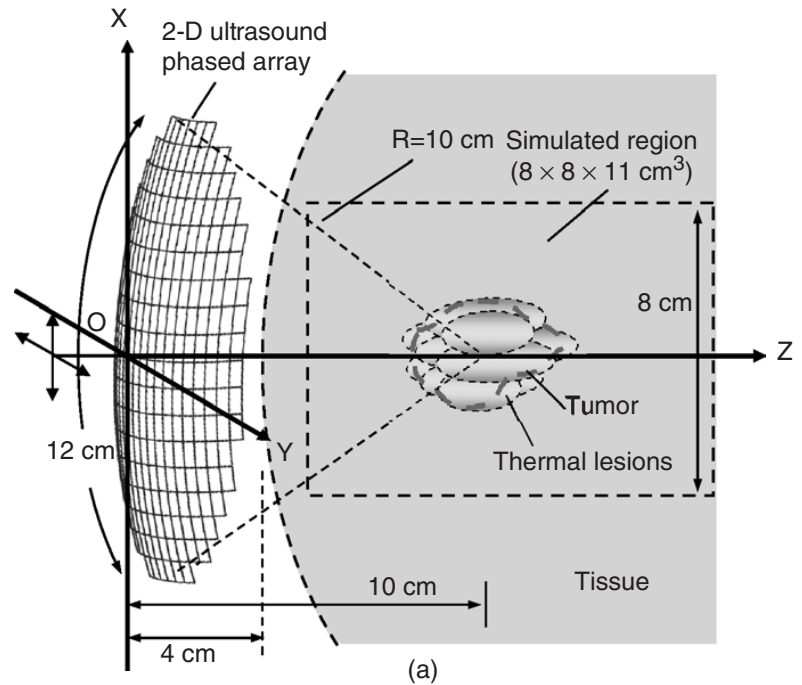

(a)
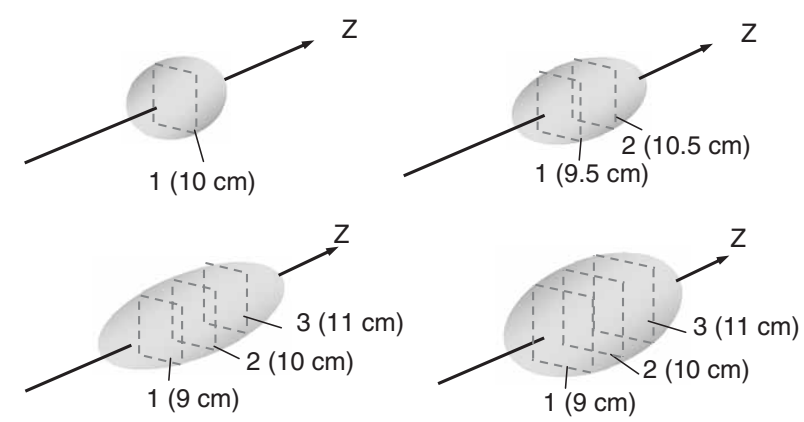

(b)

Figure 1. (a) Geometry of a 2D ultrasound phased array heating system. This $2 \mathrm{D}$ phased array was assumed to be mounted on a positioning system that can shift the array in the $x$ and $y$ directions. The target volume can be divided into several rectangular subregions and then heated sequentially; (b) four types of subregions are formed by using different numbers of scanned focal depths (in dashed regions). The former three were in $1 \times 1 \mathrm{~cm}^{2}$ of crosssectional area with 1,2 , and $3 \mathrm{~cm}$ in length, respectively. The fourth case had $1.5 \times 1.5 \mathrm{~cm}^{2}$ of cross-sectional area with $3 \mathrm{~cm}$ in length.

number can be selected to fit the tumor's length in that subregion.

Four different basic heating units were designed to fit different sizes of the divided subvolumes in the following study as shown in Figure 1(b): Three with a cross-sectional area of $1 \times 1 \mathrm{~cm}^{2}$ and lengths of 1 , 2 , and $3 \mathrm{~cm}$, and one with a cross-sectional area $1.5 \times 1.5 \mathrm{~cm}^{2}$, and $3 \mathrm{~cm}$ in length. To achieve subnecrosed volume with $1 \mathrm{~cm}$ in length, the region was scanned by single focal-depth at $z=10 \mathrm{~cm}$; to synthesize subnecrosed volume with 2 and $3 \mathrm{~cm}$ in lengths, the regions were scanned at focal depths of $z=9.5,10.5 \mathrm{~cm}$ and $z=9,10$, and $11 \mathrm{~cm}$, respectively, as shown in Figure 1(b). Moreover, to form the scanning area of $1 \times 1 \mathrm{~cm}^{2}$ and $1.5 \times 1.5 \mathrm{~cm}^{2}$ at the designated focal depth, series of multiple-focal patterns were designed. Detailed assigned focal
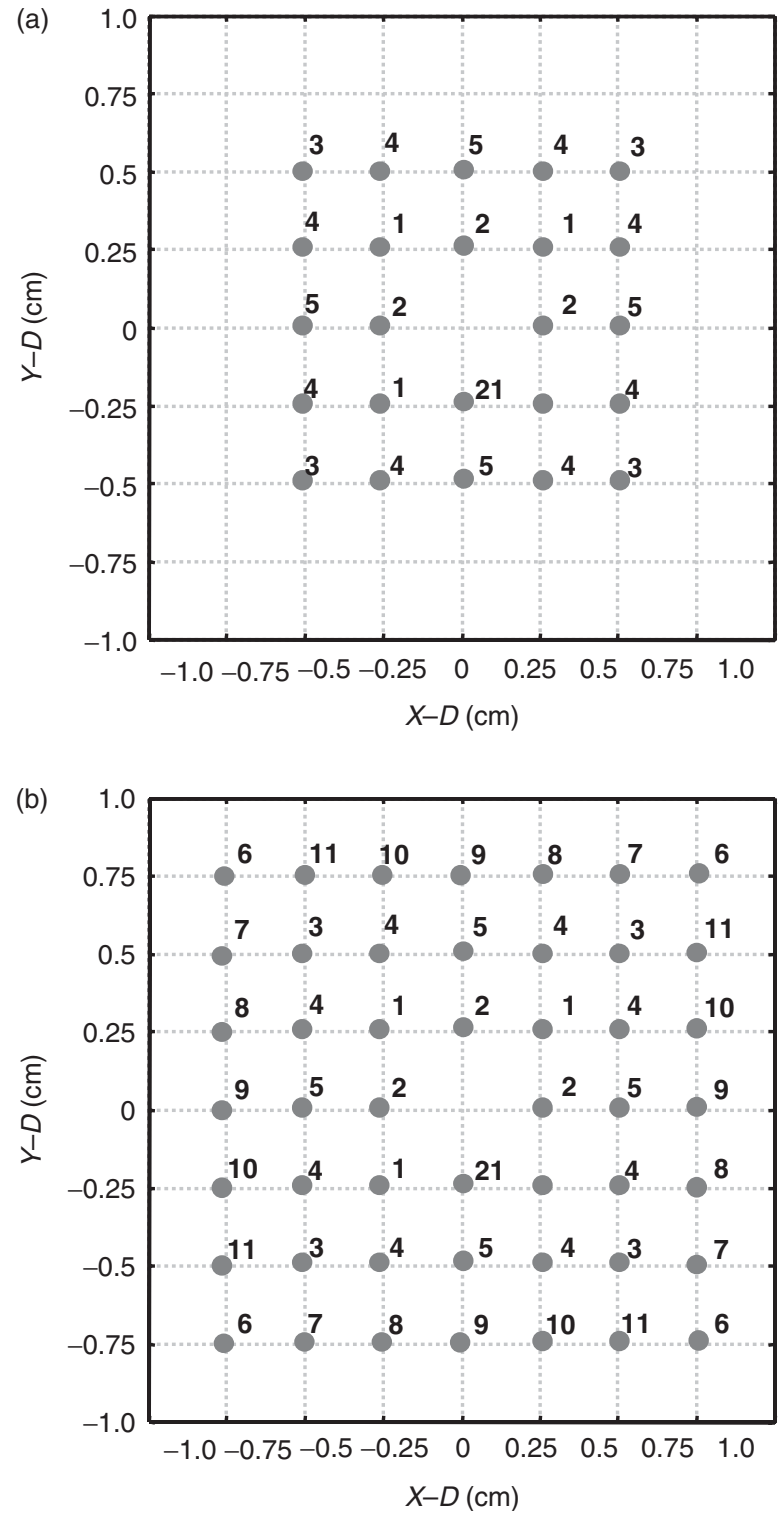

Figure 2. Focal point arrangement of each scanning plane with the scanning areas (a) $1 \times 1 \mathrm{~cm}^{2}$ and (b) $1.5 \times 1.5 \mathrm{~cm}^{2}$.

positions in each pattern and the sequence of the scanning series of the multiple-focal patterns are shown in Figure 2. The multiple-focal pattern were synthesized by using the "pseudo-inverse" method to solve the respective amplitude and phase difference for each phased array element [19]. The number of the simultaneously generated foci was restricted to be four or eight. The focal spacing after scanning was set to be $2 \mathrm{~mm}$. This was enough to provide sufficient thermal dose (TD) accumulation between foci according to Damianou and Hynynen [20].

To provide relatively uniform averaged power patterns over the target region, the used scanned patterns were output-power weighted. Here, a 
gradient-based adaptation method has been developed and was used to tune the relative weightings of the scanned patterns, in order to produce iso-TD distribution and optimally conform a assigned subvolume [21]. This method was designed based on a direct search algorithm combined with constrained least-squares optimization scheme, and can be effectively converged to the optimal solutions within a reasonable computational time $(<5 \mathrm{~min}$ for each case). The used patterns were then scaled up to reach maximal instantaneous peak intensities of $1000 \mathrm{~W} / \mathrm{cm}^{2}$ to shorten the heating duration, but low enough to prevent the occurrence of acoustic cavitation phenomenon confirmed by previous liver tissue treatment [22] and muscle treatment [23]. The switching frequency between each power pattern is set to $20 \mathrm{~Hz}$ in this study, and this was fast enough muscle tissues $[25,28]$. In this study, a conservative value of $240 \mathrm{~min}$ was chosen as threshold for target tissue complete necrosis inside of the target volume.

The tissue temperature response, $T$, can be calculated by using the Pennes' bio-heat transfer equation [29]:

$$
\rho c_{\mathrm{t}} \frac{\partial T}{\partial t}=k \nabla^{2} T-w_{\mathrm{b}} c_{\mathrm{b}}\left(T-T_{\mathrm{ar}}\right)+q
$$

where $c_{\mathrm{t}}$ and $c_{\mathrm{b}}$ were the specific heats of the tissue and the blood (both set to be $3770 \mathrm{~J} / \mathrm{kg} /{ }^{\circ} \mathrm{C}$ ), $k$ is the thermal conductivity $\left(0.56 \mathrm{~W} / \mathrm{m} /{ }^{\circ} \mathrm{C}\right)$, and $T_{\mathrm{ar}}$ was the arterial blood temperature $\left(37^{\circ} \mathrm{C}\right)$. Herein, the blood perfusion rate $w_{\mathrm{b}}(x, y, z)$ was considered to be TD dependent in Equation 3 according to Kolios et al. [30]:

$$
w_{\mathrm{b}}(x, y, z)= \begin{cases}w_{\mathrm{b} 0} & \log _{10}(\mathrm{TD}(x, y, z)) \leq 1 \\ w_{\mathrm{b} 0} \cdot\left(1-\frac{\log _{10}(\mathrm{TD}(x, y, z))-1}{2.5-1}\right), & 1<\log _{10}(\mathrm{TD}(x, y, z)) \leq 2.5 \\ 0 & \log _{10}(\mathrm{TD}(x, y, z))>2.5\end{cases}
$$

to reduce the temperature fluctuation during scanning to reach an acceptable small level [14] $\left(<1^{\circ} \mathrm{C}\right.$ when switching hundreds of focal patterns in our previous study [24]). In large volume treatment, a temperature monitoring point was set in front of the large tumor, located at $z=8 \mathrm{~cm}$ on the central $z$-axis. A constant cooling intermission period of minute was used between each heating unit sonication [17]. This was verified to be sufficient to prevent the temperature build-up in front of the target volume and cause the near-field heating problem. When treating shallower tumors, it was assumed that the phased array system has the flexibility to be repositioned along the axial direction and aligned the geometrical focal center of phased array with tumor center.

\section{Thermal dose and temperature calculation}

The TD, in terms of equivalent minutes at $43^{\circ} \mathrm{C}$, is used to estimate the necrosed tissue volume and is in form as follows 25-27:

$$
\mathrm{TD}=\int_{t_{0}}^{t_{\mathrm{f}}} R^{(T-43)} \mathrm{dt} \approx \sum_{t_{0}}^{t_{\mathrm{f}}} R^{(T-43)} \Delta t
$$

where $R=2$ for $T \geq 43^{\circ} \mathrm{C}$, and $R=4$ for $37^{\circ} \mathrm{C}<T<43^{\circ} \mathrm{C}, \Delta t$ is the time step (in min), and $t_{0}$ and $t_{\mathrm{f}}$ represent the initial and final times, respectively. The TD value required for total necrosis ranges from 25 to $240 \mathrm{~min}$ for brain to according to Kolios et al. where $w_{\mathrm{b} 0}$ was the initial blood perfusion rate which is set to be $1 \mathrm{~kg} / \mathrm{m}^{3} / \mathrm{s}$ as a reference value otherwise mentioned. To test the robustness of the proposed heating strategy among different blood flow environment, some cases with high blood perfusion rate of $10 \mathrm{~kg} / \mathrm{m}^{3} / \mathrm{s}$ was employed. This equation was solved by using a numerical finite difference method, with temperature at boundary all set to $37^{\circ} \mathrm{C}$. The time step and the grid spacing in the $x$-, $y$ - and $z$-directions (Figure 1) in program were set to be $50,0.5,0.5$, and $1 \mathrm{~mm}$, respectively.

\section{Ultrasound field calculation}

The ultrasound field calculation contains two procedures: free-field intensity calculation (no attenuation) and absorbed power distribution in attenuated medium. To calculate the ultrasonic intensity field without attenuation, the transducer was modeled as a grid of point sources. Then, the RayleighSommerfeld integral was used to sum up the contribution of each point source, $r^{\prime}$, to the point of the field at $r$ [7]. The integral was given as:

$$
I(x, y, z)=\frac{1}{2 \rho c}\left[\frac{i \rho c k}{2 \pi} \int_{S} \frac{u e^{-i k \cdot\left(r-r^{\prime}\right)}}{r-r^{\prime}} \mathrm{d} S\right]^{2}
$$

where $\rho$ is the tissue density $\left(1050 \mathrm{~kg} / \mathrm{m}^{3}\right), c$ the speed of sound $(1500 \mathrm{~m} / \mathrm{s}), k$ the wave number $(2 \pi / \lambda$, where $\lambda$ is the wave length), $u$ the complex surface 
velocity of the source, and $S$ the area of the ultrasound source. This linear model was employed since it can provide fast estimation with acceptable accuracy in homogeneous medium case [31]. Effect of nonlinear propagation, wave diffraction, and wave reflection through inhomogeneous tissue was not included here, but can be further considered by using more advanced models if necessary $[32,33]$.

Next, the absorbed power deposition, $q$, can be calculated from the free-field intensity distribution according to Arditi et al. [34]:

$$
q(x, y, z)=2 \cdot \alpha(x, y, z) \cdot I(x, y, z) \cdot e^{\int_{z_{0}}^{e_{t}}-\mu(x, y, z) \mathrm{d} z}
$$

where $\mu(x, y, z)$ was the attenuation coefficient and was considered to be TD dependent based on the experimental data of Damianou et al. [35]: optimization algorithm which was developed in our previous work [24]. The algorithm employed a constrained least-squares optimization method to solve the optimal heating condition based on maximizing the conformal index (defined as the difference between $\mathrm{CI}$ and $\mathrm{EI}_{\text {threshold }}$ ) [24]. In this study, to guarantee the complete coverage of the tumors, the algorithm were slightly modified by adding a constraint condition that can force $\mathrm{CI}$ value to reach $100 \%$.

\section{Results}

Comparison between theoretical and experimental results

Figure 3 shows the comparison of the theoretical prediction based on our proposed model (from

$$
\mu(x, y, z)= \begin{cases}\mu_{1} & \log _{10}(\mathrm{TD}(x, y, z)) \leq 2 \\ \mu_{1}+\left(\mu_{2}-\mu_{1}\right) \cdot \frac{\log _{10}(\mathrm{TD})-2}{7-2}, & 2<\log _{10}(\mathrm{TD}(x, y, z)) \leq 7 \\ \mu_{2} & \log _{10}(\mathrm{TD}(x, y, z))>7\end{cases}
$$

where $\mu_{1}=4.1$ and $\mu_{2}=8.9 \mathrm{~Np} / \mathrm{m} / \mathrm{MHz} . \alpha(x, y, z)$ is the absorption coefficient which was is assumed to be $90 \%$ of the attenuation value $(10 \%$ of it is assumed to be scattered) according to Gertner et al. [36].

\section{Evaluation of treatment conformability and thermal dose optimization}

To evaluate the treatment conformability, tumors covered by the generated thermal lesions, as well as the accompanying normal tissue damage, should be both considered. Here, two indexes used in 3D conformal ultrasound hyperthermia, coverage index, $\mathrm{CI}$, and an external volume index, $\mathrm{EI}_{\text {threshold, were }}$ used [37]:

$$
\begin{gathered}
\mathrm{CI}=\frac{\mathrm{PTV}_{\mathrm{TD} \geq 240}}{\mathrm{PTV}} \times 100 \% \\
\mathrm{EI}_{\text {threshold }}=\frac{\mathrm{NPTV}_{\mathrm{TD} \geq \text { threshold }}}{\mathrm{PTV}} \times 100 \%
\end{gathered}
$$

where PTV was the planning target volume (i.e., tumor region), $\mathrm{PTV}_{\mathrm{TD}} \geq 240$ is the volume inside the PTV with $\mathrm{TD} \geq 240 \mathrm{~min}$, and $\mathrm{NPTV}_{\mathrm{TD}} \geq$ threshold is the non-PTV (i.e., normal tissue region) with TD larger than a given TD threshold. In this study, two TD threshold values of 60 and $240 \mathrm{~min}$ were used in $\mathrm{EI}_{\text {threshold }}$, and were denoted as $\mathrm{EI}_{240}$ and $\mathrm{EI}_{60}$, respectively.

To optimally determine the heating units with a designated TD distribution, we employed a TD
Equations 1-6) to experimental results conducted by Daum and Hynynen [14]. The considered phased array in our study was set to be identical to their study. Also, the initial tissue thermal property was referred form their suggested value as follows [14]: $\left(k=0.48 \mathrm{~W} / \mathrm{m} / \mathrm{C}, c_{\mathrm{t}}=c_{\mathrm{b}}=3770 \mathrm{~J} / \mathrm{kg} /{ }^{\circ} \mathrm{C}, \rho=998 \mathrm{~kg} / \mathrm{m}^{3}\right.$, $\left.\mu_{1}=4.1 \mathrm{~Np} / \mathrm{m}, \quad w_{\mathrm{b} 0}=1 \mathrm{~kg} / \mathrm{m}^{3} / \mathrm{s}\right)$. In their experiment, the focal area produced in porcine thigh muscle was $1 \times 1 \mathrm{~cm}^{2}$ (performed by switching five multiple-foci patterns) and the focal depth was about $5 \mathrm{~cm}$ beneath the skin. Two simulations were conducted to compare with the experimental data: The first one was to assume that the blood perfusion rate and the attenuation were fixed to be constants (i.e., $w_{\mathrm{b}}=w_{\mathrm{b} 0}$ in Equation 3 and $\mu=\mu_{1}$ in Equation 6; represented in dashed lines in Figure 3), and the second one assumed that the blood perfusion rate and the attenuation were TD dependent (represented in real lines in Figure 3). As shown in Figure 3(a) and (b), the two simulated temperature distributions were both close to the experimental one (maximal deviation $<5^{\circ} \mathrm{C}$ in front of the focal depth and $<2^{\circ} \mathrm{C}$ at the focal depth), and has a higher peak temperature of $2-3^{\circ} \mathrm{C}$ in $\mathrm{TD}$ dependent parameter case. The temperature responses in Figure 3(c) and (d) (at focal depth $z=9 \mathrm{~cm}$ and $z=6 \mathrm{~cm}$ ) also showed that predicted temperature responses in the "cooling" period can have closer estimation after considering thermal-dependent tissue property change. 

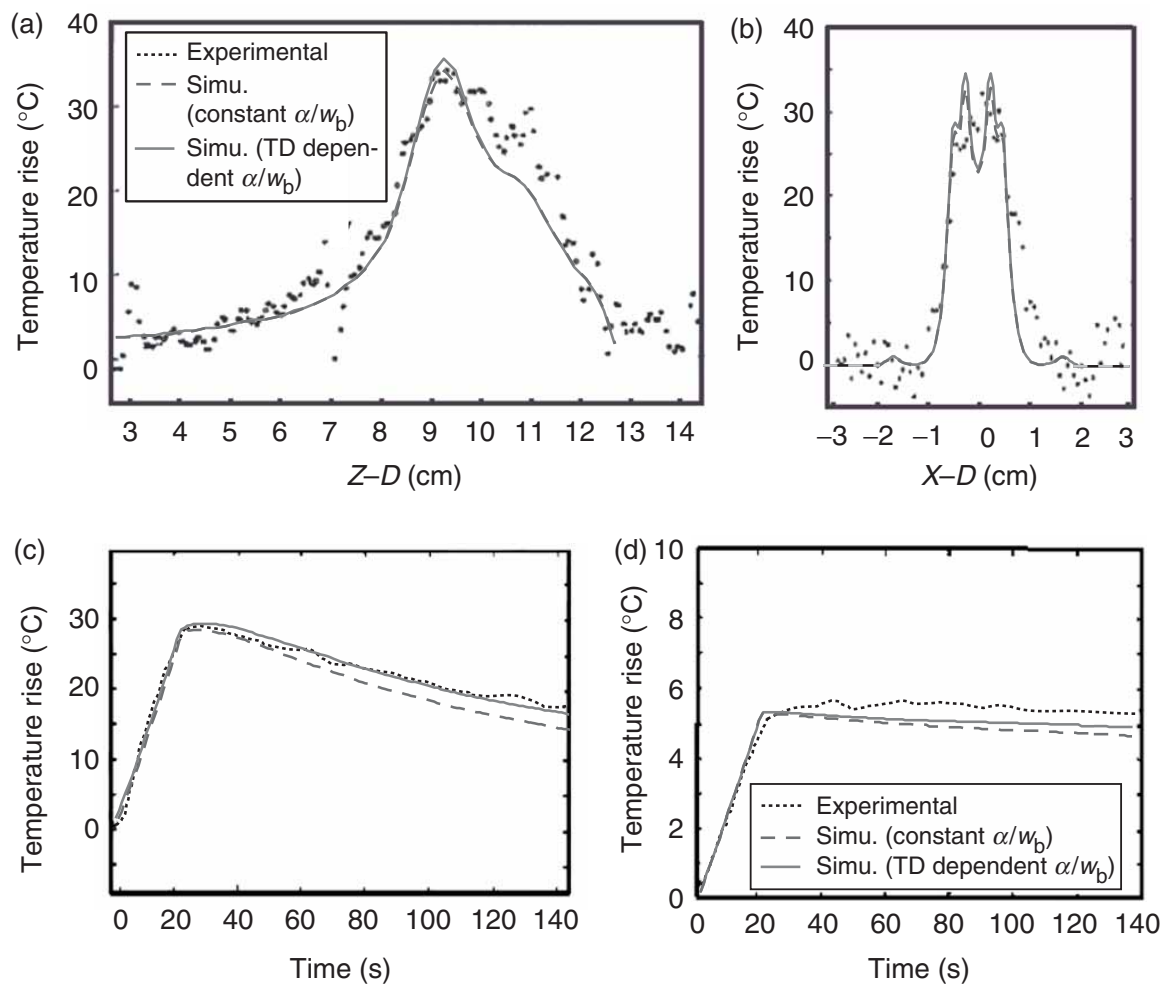

Figure 3. Simulated temperature profiles (using constant/thermal-dependent tissue parameters) compared with the experimental data of a 256-element 2D phased array system [14]. (a) and (b) spatial temperature distribution at the end of sonication $(t=20 \mathrm{~s})$, (c) temperature response at the focal depth $(z=9 \mathrm{~cm})$ and (d) at the pre-focal region $(z=6 \mathrm{~cm})$.

Single subregion heating using multiple focal-depth scanning

The feasibility of using multiple focal-depth scanning to form different sizes of subregion was analyzed first. Figure 4(a)-(c) shows the iso-TD surface view of the formed thermal lesions by electrically switching and scanning the target region with single, two, and three focal depths in $1 \times 1 \mathrm{~cm}^{2}$ of focal area $\left(w_{\mathrm{b} 0}=1 \mathrm{~kg} / \mathrm{m}^{3} / \mathrm{s}\right)$. Figure $4(\mathrm{~d})$ shows the case of three-focal depth with $1.5 \times 1.5 \mathrm{~cm}^{2}$ of focal area $\left(w_{\mathrm{b} 0}=1 \mathrm{~kg} / \mathrm{m}^{3} / \mathrm{s}\right)$. In Figure 5 we also show the corresponding 2D TD contours (both $X-Z$ plane and $X-Y$ plane). Here, both $\mathrm{TD}=60$ and $240 \mathrm{~min}$ surfaces were presented. The required exposure time, maximum temperature, maximum $\mathrm{TD}$ and resulting EI value are listed in Table I. It showed that the generated lesions' length can be well-controlled by using different focal depth numbers. Also, in Figure 4(d), it can be observed that the lesion generated by $1.5 \times 1.5 \mathrm{~cm}^{2}$ can have larger crosssectional area than the case of $1 \times 1 \mathrm{~cm}^{2}$ shown in Figure $4(\mathrm{c})$. The peak temperature at the end of sonication from case 1 to 4 were within $10^{\circ} \mathrm{C}$ $\left(65.6-73.8^{\circ} \mathrm{C}\right)$ even when the formed lesion sizes has a 5-fold variation. Case 5 shown in Figures 4(e), 5(i) and 5(j) tested the applicability of the proposed scheme at high blood perfusion condition $\left(w_{\mathrm{b} 0}=10 \mathrm{~kg} / \mathrm{m}^{3} / \mathrm{s}\right)$, comparing with case 4 [Figures 4(d), 5(g), and 5(h)]. The heating unit of $1.5 \times 1.5 \mathrm{~cm}^{2}$ with three focal depths was selected to be tested due to that blood perfusion change has more apparent influence on larger heating units. Results showed that, at high blood perfusion condition, a $1.5 \times 1.5 \times 3 \mathrm{~cm}^{3}$ heating unit was still able to be successfully produced. From Table I, it was also noted that the peak temperature and TD was increased $\left(7^{\circ} \mathrm{C}\right.$ increase compared with case 4$)$ and TD was increased about two orders), which implies that the temperature/TD uniformity was worse in high blood perfusion cases $[8,10]$. Also, the energy dissipation was faster in high blood perfusion case, leading to that the heating time was extensively increased (from $170 \mathrm{~s}$ to $250 \mathrm{~s}$ ) and TD distributions became steeper (see Figure $4 \mathrm{~d}$ and e, or Figure $5 \mathrm{~g}$ and i).

\section{Effect of large-volume treatment and heating sequence selection}

The proposed heating strategy applied for larger tumor treatment is presented next. Here, a $3 \times 3 \times 3 \mathrm{~cm}^{3}$ volume was regarded as the PTV. To successfully treat the entire volume, the PTV was 


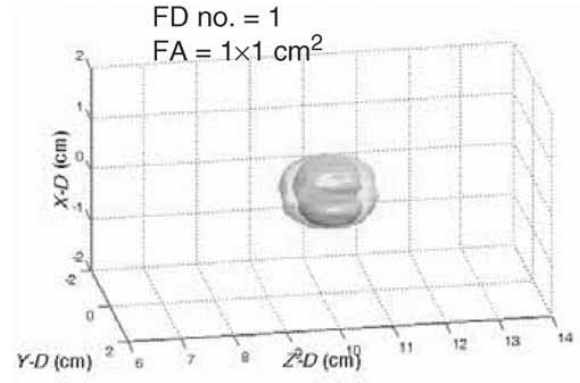

(a)

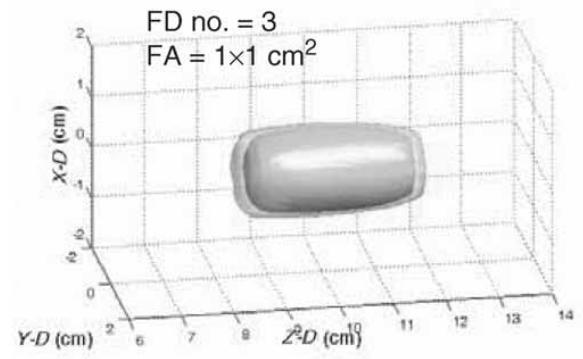

(c)

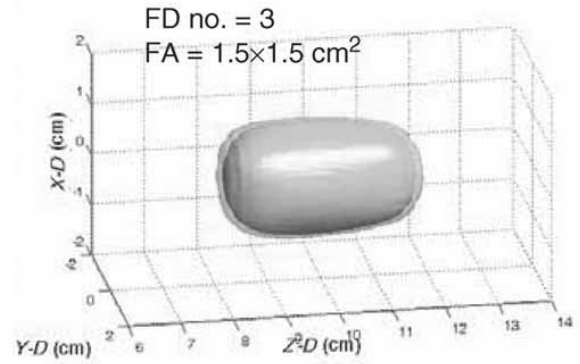

(e)

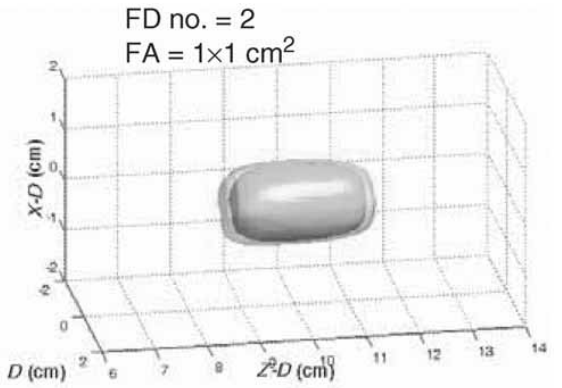

(b)

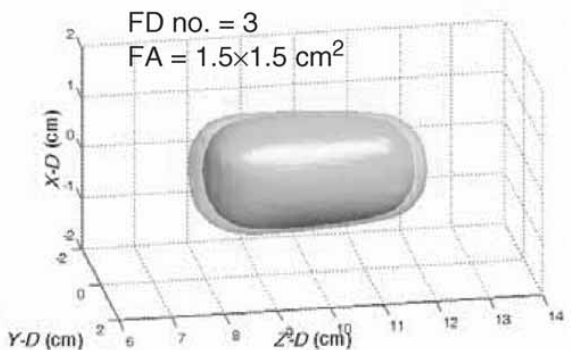

(d)

Figure 4. Three-dimensional surface views of the formed thermal lesions (in TD $=60$ and $240 \mathrm{~min}$ ) to cover subvolumes of (a) $1 \times 1 \times 1 \mathrm{~cm}^{3}$, (b) $1 \times 1 \times 2 \mathrm{~cm}^{3}$, (c) $1 \times 1 \times 3 \mathrm{~cm}^{3}$, (d) $1.5 \times 1.5 \times 3 \mathrm{~cm}^{3}$ at $1 \mathrm{~kg} / \mathrm{m}^{3} / \mathrm{s}$ of blood perfusion rate and (e) another $1.5 \times 1.5 \times 3 \mathrm{~cm}^{3}$ subvolume at $10 \mathrm{~kg} / \mathrm{m}^{3} / \mathrm{s}$.

first divided into nine $1 \times 1 \times 3 \mathrm{~cm}^{3}$ subvolumes. Each subvolume was individually heated by the designed multiple-focal-depth scanning units shown in Figure 4(c). The first sequence (denoted as case 6) shifted the transducer with the shortest possible distance for each time, and the second sequence (denoted as case 7) shifted the transducer with the longest distance possible. The two heating sequences and the generated thermal lesions were shown in Figure 6(a) and (b), and their corresponding 2D TD distributions shown in Figure 7, respectively, and the detail information was listed in Table I (cases 6 and 7). It can be shown that, as the shifting distance between two consecutive exposures increases, the normal tissue damage can be better controlled (i.e., $\mathrm{EI}_{240}$ and $\mathrm{EI}_{60}$ was decreased from $49.8 \%$ to $34.3 \%$ and $71 \%$ to $55.3 \%$, respectively) under the basis of complete PTV coverage (i.e., CI reached 100\%). Moreover, the peak temperature, the peak TD value, $\mathrm{EI}_{240}$ and $\mathrm{EI}_{60}$ value, and the treatment time were all found to be reduced (from $78.7^{\circ} \mathrm{C}$ to $74.3^{\circ} \mathrm{C}$, from $2.3 \times 10^{10} \mathrm{~min}$ to $6.1 \times 10^{8} \mathrm{~min}$, from $44.5 \%$ to $33.8 \%$, and from $44.5 \mathrm{~min}$ to $33.8 \mathrm{~min}$, respectively). This was because the temperature accumulation in front of the tumor can be smaller if the next subregion to be heated is not connected to that currently heated.

\section{Effect of different cross-sectional area}

To further show the influence of selecting heating units with different cross-sectional areas, in case 8, the $3 \times 3 \times 3 \mathrm{~cm}^{3}$ PTV was divided into four $1.5 \times 1.5 \times 3 \mathrm{~cm}^{3}$ subvolumes. Then, the heating units shown in Figure 4(d) were respectively used to treat the defined subvolumes. The heating sequence and the formed thermal lesion of this case was shown in Figure 6(c), with its corresponding 2D TD contours shown in Figure 7, and the treatment results are listed Table I. It was found that, when 

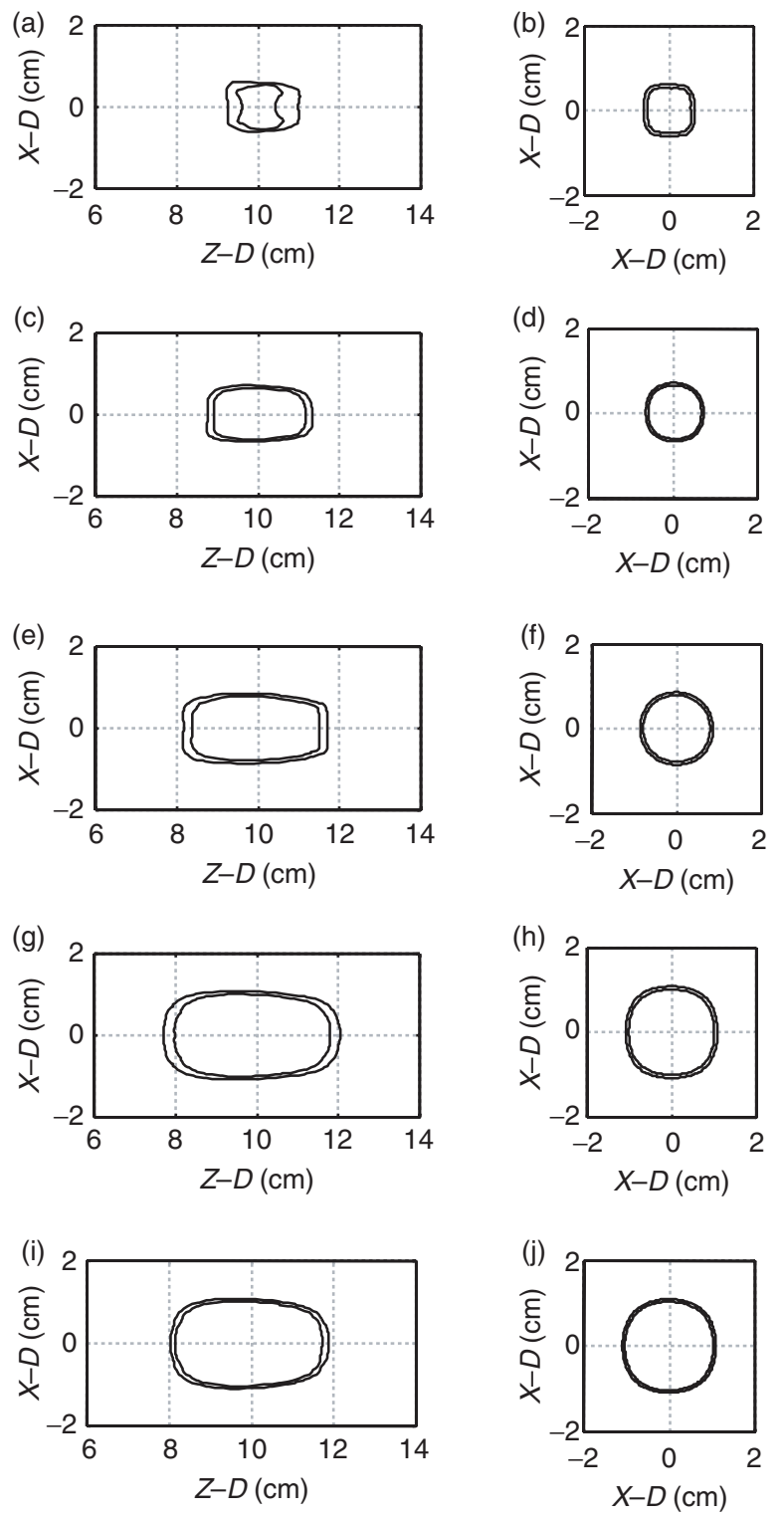

Figure 5. Two-dimensional TD contour distributions ( $\mathrm{TD}=60$ and $240 \mathrm{~min}$ were shown) for Figure 4 . Left columns show the $X-Z$ plane $(Y=0 \mathrm{~cm})$ distributions and the right columns show the $X-Y$ plane $(Z=10 \mathrm{~cm})$ distributions. Outer and inner contour for each subplot represent $\mathrm{TD}=60$ and $240 \mathrm{~min}$, respectively.

using larger subregions to perform the treatment, the required treatment time can have a $16 \%$ reduction (28.1 min compared with $33.8 \mathrm{~min}$ ) due to fewer exposures and intervening cooling times. However, the $\mathrm{EI}_{240}$ and $\mathrm{EI}_{60}$ value of the nine subregion case was higher $\left(60 \%\right.$ compared with $34 \%$ for $\mathrm{EI}_{240}$ and $76 \%$ to $55 \%$ for $\mathrm{EI}_{60}$ when reaching $\mathrm{CI}=100 \%$ ). This is because the generated lesion is of ellipsoid shape, and enlarging the subregions also induces a wider gap between the formed lesions. This led to more tissue damage and hence worsened the treatment conformability.
In case 9, the $3 \times 3 \times 3 \mathrm{~cm}^{3}$ PTV conformed by four $1.5 \times 1.5 \times 3 \mathrm{~cm}^{3}$ subheating units was also tested under high blood perfusion condition $\left(10 \mathrm{~kg} / \mathrm{m}^{3} / \mathrm{s}\right)$, and the results were shown in Figures $6(\mathrm{~d}), 7(\mathrm{~g})$ and $7(\mathrm{~h})$. The peak temperature in the high perfusion condition was about $9^{\circ} \mathrm{C}$ higher than in case [8]. With the same $\mathrm{CI}=100 \%$ condition, the $\mathrm{EI}_{240}$ was similar while the $\mathrm{EI}_{60}$ was surprisingly better in high blood perfusion case (63\% compared with $76 \%$ ). The total treatment time in high perfusion condition was found to be longer since the sonication time for each subheating unit was longer than low perfusion one $(250 \mathrm{~s}$ compared with 170 s).

\section{Feasibility to treat irregular tumors}

To show the feasibility of using this strategy to treat real tumors, an irregular shape PTV was designed to be tested first, and then a practical breast tumor case from Leibel and Phillips [37] was considered to be PTV and tested next. For the designed shape PTV, the $1 \times 1 \times 1,1 \times 1 \times 2$, and $1 \times 1 \times 3 \mathrm{~cm}^{3}$ subheating units were all employed and sequentially heated to conform the target region. The thermal properties were set to be the same as cases 6 to 8 (low blood perfusion condition), and the treatment results were shown in Figures 6, 7(i), and (j) with the data listed in Table I (denoted as case 10). It was shown that, by utilizing suitable sub-heating unit and the proposed scheme, irregular PTV can be still covered by $240-$ min iso-TD region while improving the treatment conformability as possible. However, due to its complex PTV, the treatment conformability was worse than the above $3 \times 3 \times 3 \mathrm{~cm}^{3}$ PTV treatment cases $\left(\mathrm{EI}_{240}\right.$ and $\mathrm{EI}_{60}$ reached $69 \%$ and $87 \%$, respectively).

In the real breast PTV case, the acoustical and thermal parameters were referred to previous studies by $\mathrm{Lu}[14,18]$ and as follows: $\mu_{1}=6 \mathrm{~Np} / \mathrm{m}$, $k=0.5 \mathrm{~W} / \mathrm{m} /{ }^{\circ} \mathrm{C}, \quad w_{\mathrm{b} 0}=1.7 \mathrm{~kg} / \mathrm{m}^{3} / \mathrm{s}, \quad c_{\mathrm{t}}=c_{\mathrm{b}}=$ $4000 \mathrm{~J} / \mathrm{kg} /{ }^{\circ} \mathrm{C}$. The geometrical relationship between treatment location and phased array system as well as the treatment result are shown in Figure 8(a). To see the influence of power incident direction to treatment conformability and treatment time, two powerincident directions were selected either to align the PTV to have longer dimension along the axial direction (denoted as incident direction 1) or along the cross-sectional direction (denoted as incident direction 2) of the $2 \mathrm{D}$ phased array. In incident direction 1, the PTV was divided into five subregions; in incident direction 2 , the number of subregion was increased to seven, and each of it was relatively shorter in length than that of incident direction 1. Thermal lesions formed in these two cases were shown in Figure 8(b) and (c), and the 
Table I. Comparison of treatment results for different heating units and larger thermal lesions to conform a $3 \times 3 \times 3 \mathrm{~cm}^{3}$ PTV as well as an irregular PTV.

\begin{tabular}{ccccccccccc}
\hline Case & $\begin{array}{c}\text { PTV } \\
\left(\mathrm{cm}^{3}\right)\end{array}$ & $\begin{array}{c}\text { Focal } \\
\text { depth }(\mathrm{cm})\end{array}$ & $\begin{array}{c}\text { Pattern } \\
\text { no. }\end{array}$ & $\begin{array}{c}\text { Subreg. } \\
\text { no. }\end{array}$ & $t_{\text {on }}(\mathrm{s} / \mathrm{min})$ & $T_{\max }\left({ }^{\circ} \mathrm{C}\right)$ & $\begin{array}{c}\mathrm{TD}_{\max } \\
(\min )\end{array}$ & $\begin{array}{c}\mathrm{CI}_{240} \\
(\%)\end{array}$ & $\begin{array}{c}\mathrm{EI}_{240} \\
(\%)\end{array}$ & $\begin{array}{c}\mathrm{EI}_{60}(\%) \\
(\%)\end{array}$ \\
\hline 1 & $1 \times 1 \times 1$ & 12 & 5 & - & $40 \mathrm{~s}$ & 65.6 & $2.9 \times 10^{5}$ & - & - & - \\
2 & $1 \times 1 \times 2$ & $11.5 / 12.5$ & 10 & - & $45 \mathrm{~s}$ & 68.7 & $4.3 \times 10^{6}$ & - & - & - \\
3 & $1 \times 1 \times 3$ & $11 / 12 / 13$ & 15 & - & $70 \mathrm{~s}$ & 71.2 & $8.4 \times 10^{7}$ & - & - & - \\
4 & $1.5 \times 1.5 \times 3$ & $11 / 12 / 13$ & 33 & - & $170 \mathrm{~s}$ & 73.8 & $4.0 \times 10^{8}$ & - & - & - \\
5 & $1.5 \times 1.5 \times 3$ & $11 / 12 / 13$ & 33 & - & $250 \mathrm{~s}$ & 80.6 & $6.5 \times 10^{10}$ & - & - & - \\
6 & $3 \times 3 \times 3$ & -1 & - & 9 & $44.5 \mathrm{~min}$ & 78.7 & $2.3 \times 10^{10}$ & 100 & 49.8 & 71.0 \\
7 & $3 \times 3 \times 3$ & $-{ }^{1}$ & - & 9 & $33.8 \mathrm{~min}$ & 74.3 & $6.1 \times 10^{8}$ & 100 & 34.3 & 55.3 \\
8 & $3 \times 3 \times 3$ & $-{ }^{2}$ & - & 4 & $28.1 \mathrm{~min}$ & 77.2 & $7.5 \times 10^{9}$ & 100 & 60.3 & 76.4 \\
9 & $3 \times 3 \times 3$ & $-{ }^{2}$ & - & 4 & $31.5 \mathrm{~min}$ & 86.7 & $1.2 \times 10^{13}$ & 100 & 57.1 & 63.3 \\
10 & Irregular $1^{3}$ & -4 & - & 9 & $26.2 \mathrm{~min}$ & 79.1 & $6.0 \times 10^{10}$ & 100 & 69.1 & 87.2 \\
11 & Irregular 2 & -4 & - & 4 & $14.4 \mathrm{~min}$ & 73.1 & $2.9 \times 10^{8}$ & 100 & 33.8 & 70.1 \\
12 & Irregular $2^{5}$ & -4 & - & 7 & $23.5 \mathrm{~min}$ & 72.4 & $1.7 \times 10^{8}$ & 100 & 96.2 & 136.7 \\
\hline
\end{tabular}

${ }^{1}$ Power setting in case 3 is used to sequentially heat nine $1 \times 1 \times 3 \mathrm{~cm}^{3}$ subregions; ${ }^{2}$ Power setting in case 4 is used to sequentially heat four $1.5 \times 1.5 \times 3 \mathrm{~cm}^{3}$ subregions; ${ }^{3}$ See Figure 6 ; ${ }^{4}$ Power setting in case 1,2 , and 3 are used alternatively to sequentially heat various lengths of subvolumes to form irregular volume; ${ }^{5}$ See Figure 8.

(PTV $=$ Planning target volume, $t_{\mathrm{on}}=$ heating time, $t_{\max }=$ maximal temperature, $\mathrm{TD}_{\max }=$ maximal $\mathrm{TD}, \mathrm{CI}_{240}=$ coverage index using $\mathrm{TD}=240 \mathrm{~min}$ as threshold, $\mathrm{EI}_{60}$ and $\mathrm{EI}_{240}=$ external volume index using $\mathrm{TD}=60$ or $240 \mathrm{~min}$ as thresholds, respectively). Cases 1-4 show the results of single exposure under the reference blood perfusion rate $\left(1 \mathrm{~kg} / \mathrm{m}^{3} / \mathrm{s}\right.$; case 5 shows a high blood perfusion case $\left(10 \mathrm{~kg} / \mathrm{m}^{3} / \mathrm{s}\right)$ compared with case 4 ; case 6,7 , and 8 show the results of treating a large cubic volumes $\left(3 \times 3 \times 3 \mathrm{~cm}^{3}\right)$ by dividing into 9 and 4 subregions, respectively, under the reference blood perfusion rate $\left(1 \mathrm{~kg} / \mathrm{m}^{3} / \mathrm{s}\right)$; case 9 show a high blood perfusion case $\left(10 \mathrm{~kg} / \mathrm{m}^{3} / \mathrm{s}\right)$ compared with case 8 ; case 10 is a irregular target volume treatment, and cases 11 and 12 are results of a irregular real tumor treatment.

results were also listed in Table I (cases 11 and 12). Results in Figure 8 and Table I showed that the treatment time prolongs as the number of intervening cooling period increases. Moreover, the treatment conformability was much worse in the case of incident direction 2 (the EI value is almost three times higher than the case of incident direction 1). This can be explained from that using shorter heating unit provided less benefit of the proposed multiplefocal-depth scanning strategy. Also, shorter heating units were difficult in the lesion length control, which resulted in more thermal lesion extension toward skin worsening the treatment conformability.

\section{Discussion}

\section{Significance of this study}

In this study, strategy of using multiple focal-depth scanning and sequential heating to perform large tumor treatment was successfully implemented in a $2 \mathrm{D}$ ultrasound phased array system. Compared with the existing heating strategy, this method offered both short treatment time and high treatment conformability. For the issue of treatment time, the heating rate in Daum and Hynynen [13] and Wu and Sherar [13] is about $0.26 \mathrm{~cm}^{3} / \mathrm{min}$ in treating $3 \times 3 \times 3 \mathrm{~cm}^{3}$ and $2 \times 2 \times 2 \mathrm{~cm}^{3}$ cubic volumes, respectively. In this study, it was shown that the treatment time can be shortened to $28-33 \mathrm{~min}$ for a $3 \times 3 \times 3 \mathrm{~cm}^{3}$ PTV treatment. In another words, the tissue necrosed rate were 0.81 to $0.96 \mathrm{~cm}^{3} / \mathrm{min}$, which was about 3-fold higher than previous strategies. Maugenot et al. also showed that by performing spiral trajectory scanning can produce the lesions with high tissue necrosed rate about $0.87 \mathrm{~cm}^{3} / \mathrm{min}$ in unoptimized case and can $>1 \mathrm{~cm}^{3} /$ min after trajectory optimization in their $2 \mathrm{~cm}$ diameter sphere case [15]. This value was similar to our study, and it also shows that the superiority of using scanning has high potential to provide a fast heating procedure for large tumor treatments.

On the issue of treatment conformability, in Wu and Sherar $[13,19]$, the CI values ranged from $74 \%$ to $79 \%$ (no EI value provided in their data). Fan and Hynynen showed that, by using a single-focused pattern scanning with the introduction of cooling intermission periods, the CI value can be close to $100 \%$ with little EI value; however, the resulting treatment time can be extended to be several hours. In our strategy, the CI can be reached $100 \%$ for each case while the EI value was still at a reasonable level. This showed the feasibility and potential of using this strategy to conform irregular volumes without sacrificing the treatment time. Although it was still unproven to form lesions of arbitrary shape, this strategy gives a possible solution to generate large thermal lesions offering short treatment time and high treatment conformability for different tumor shapes.

\section{Potential factors relevant to treatment time and treatment conformability}

In section 3, we have demonstrated critical factors that relates to the treatment time and treatment 


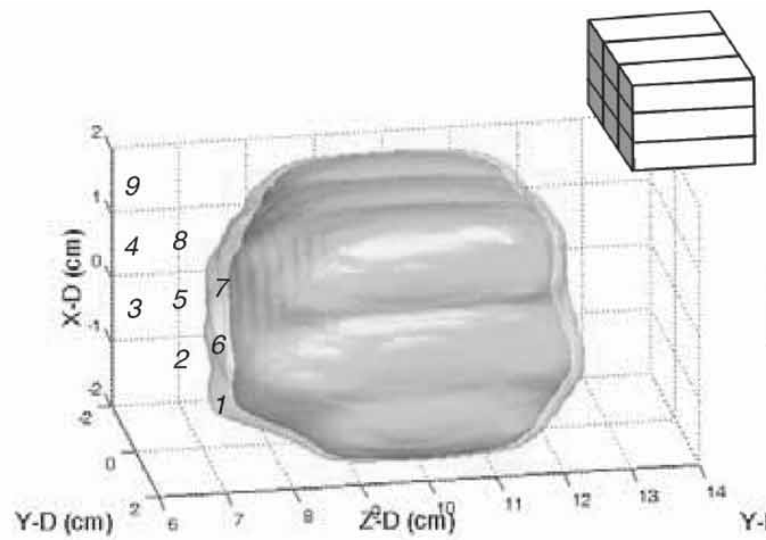

(a)

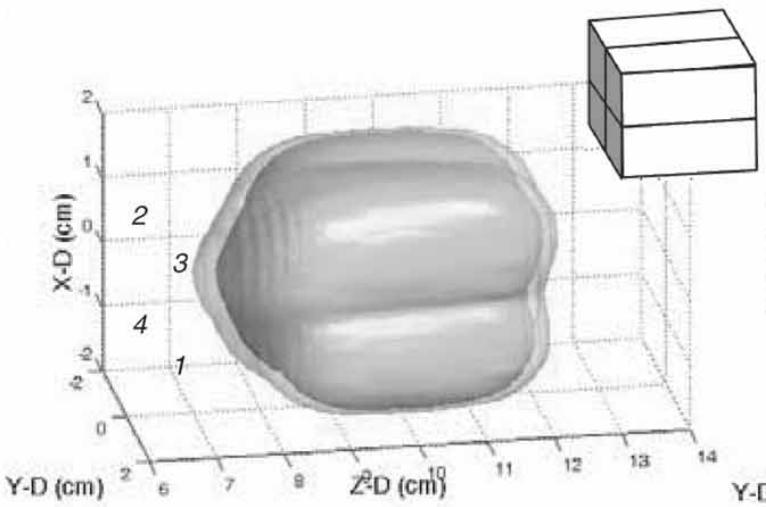

(c)

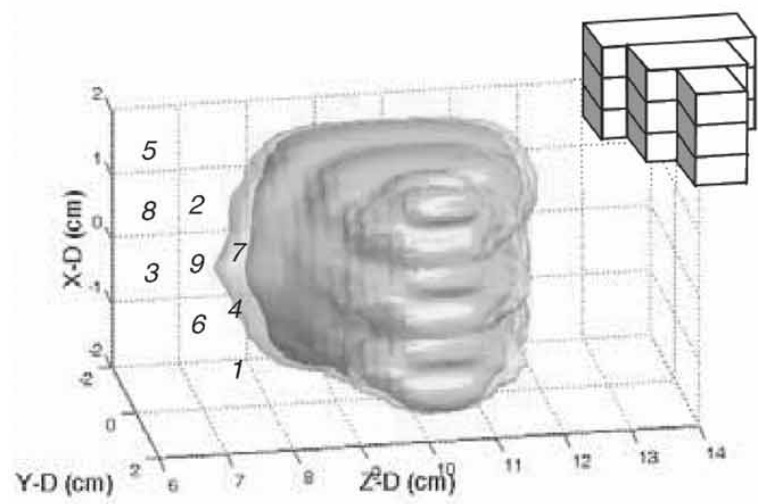

(e)

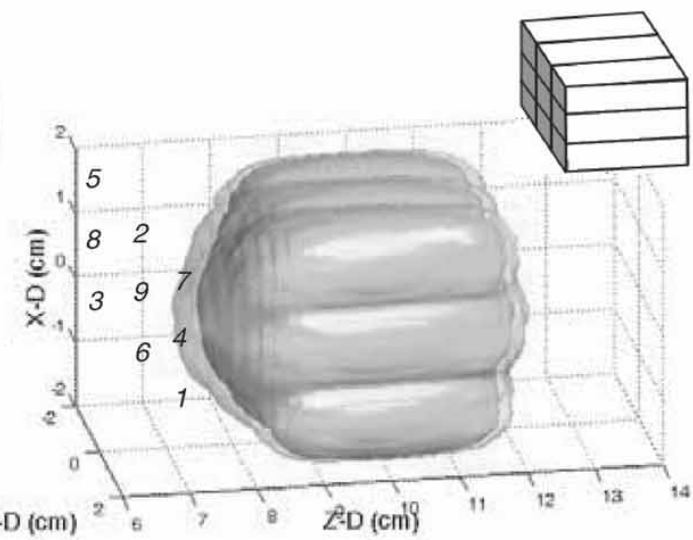

(b)

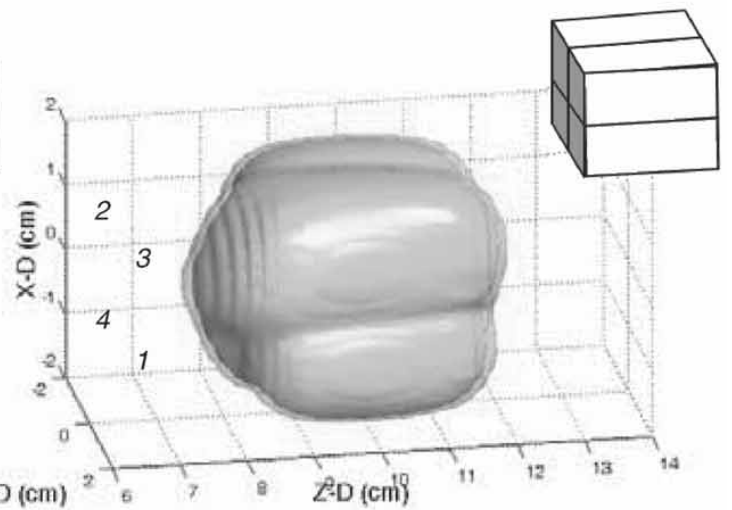

(d)

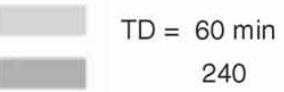

Figure 6. Three-dimensional surface views of the formed thermal lesions (in TD=60 and $240 \mathrm{~min}$ ) in: (a) and (b) two different heating sequences to conform a $3 \times 3 \times 3 \mathrm{~cm}^{3}$ cubic volume by sequentially heating nine $1 \times 1 \times 3 \mathrm{~cm}^{3}$ subvolumes at $1 \mathrm{~kg} / \mathrm{m}^{3} / \mathrm{s}$ of blood perfusion rate; (c) and (d) conforming a $3 \times 3 \times 3 \mathrm{~cm}^{3}$ cubic volume by sequentially heating four $1.5 \times 1.5 \times 3 \mathrm{~cm}^{3}$ subvolumes at 1 and $10 \mathrm{~kg} / \mathrm{m}^{3} / \mathrm{s}$ of blood perfusion rates, respectively; (e) conforming an irregular volumes by sequentially heating $1 \times 1 \times 1,1 \times 1 \times 2$, and $1 \times 1 \times 3 \mathrm{~cm}^{3}$ subvolumes. The numbers were denoted as the sequence of each subvolume heating, and a 3D cartoon object located at upper-right corner of each subplot represents the shapes and heating unit divisions to the entire target volume.

conformability, which include the sequence of the subvolumes been heated, the size of used subheating unit, blood perfusion condition, and the PTV irregularity. The selection of cooling periods between subregions, without emphasizing in our analysis, may also be another relevant factor.
A shorter cooling period between a subregion's heating intervals can shorten the total treatment time. In this study, a conservative cooling intermission period of at least $3 \mathrm{~min}$ was used since the determination of the optimal cooling period was not obvious and may be complex. The required time 
(a)

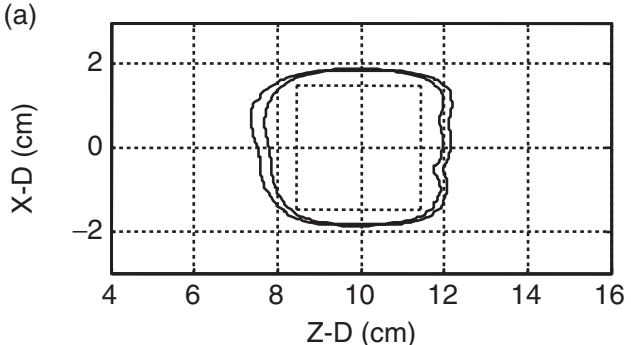

(c)

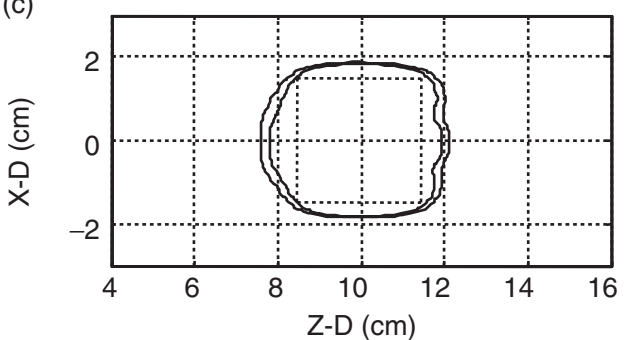

(e)

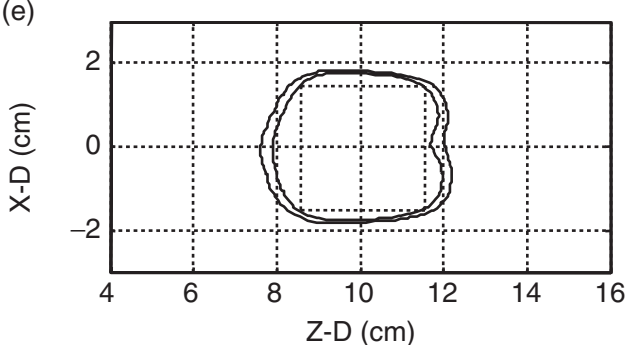

(g)

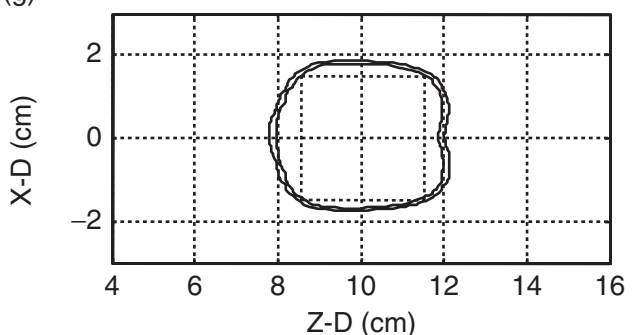

(i )

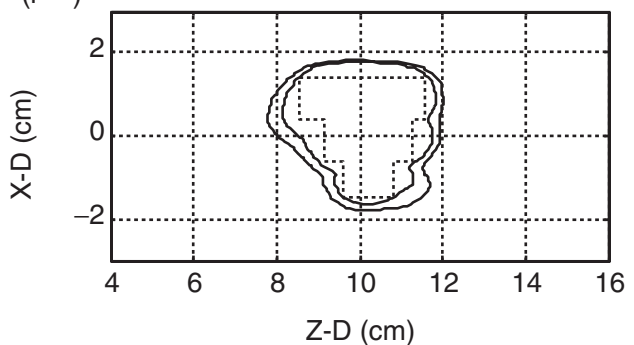

(b)

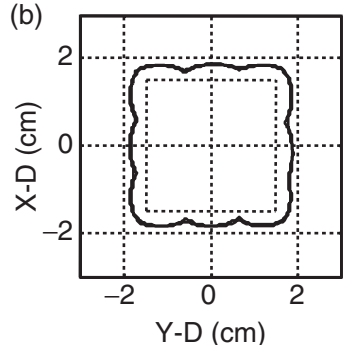

(d)

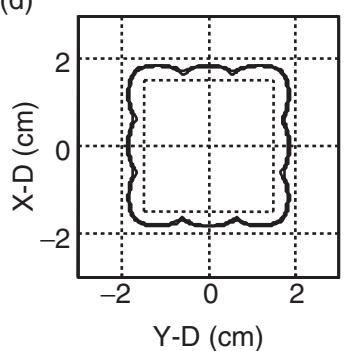

(f)

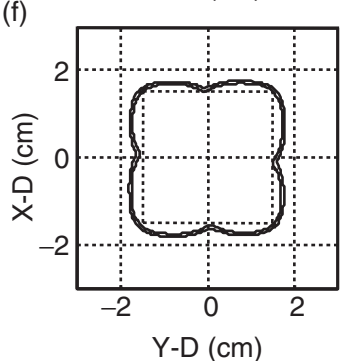

(h)

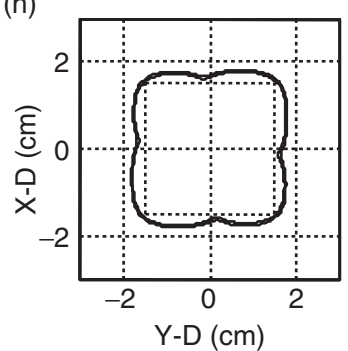

(j)

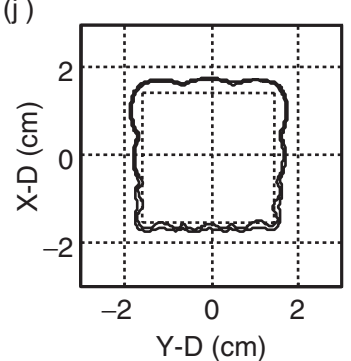

Figure 7. Two-dimensional TD contour distributions ( $T D=60$ and $240 \mathrm{~min}$ were shown) for Figure 6. Left columns show the $X-Z$ plane $(Y=0 \mathrm{~cm})$ distributions and the right columns show the $X-Y$ plane $(Z=10 \mathrm{~cm})$ distributions. Rectangular regions drawn in dashed lines represent the target volume regions appeared in individual subplots. Outer and inner contour for each subplot represent $\mathrm{TD}=60$ and $240 \mathrm{~min}$, respectively.

between consecutive subvolume sonications in order to prevent heat accumulation for intervening normal tissue relates to the selected subheating unit dimension, the heating sequence, the blood perfusion conditions, or others. For example, in case 9 $\left(3 \times 3 \times 3 \mathrm{~cm}^{3}\right.$ with four subheating unit treatment in $10 \mathrm{~kg} / \mathrm{m}^{3} / \mathrm{s}$, compared with case 8 in $1 \mathrm{~kg} / \mathrm{m}^{3} / \mathrm{s}$ ), a high perfusion condition led to sonication time increase to produce sufficient necrosis area to cover the subvolume ( $250 \mathrm{~s}$ compared with $170 \mathrm{~s}$ ), and hence prolonged the total treatment time (from 28.1 to $31.5 \mathrm{~min}$ ). However, it was found that the $3-\mathrm{min}$ cooling time between each sub-heating unit sonication can be further shortened due to the fast heat 


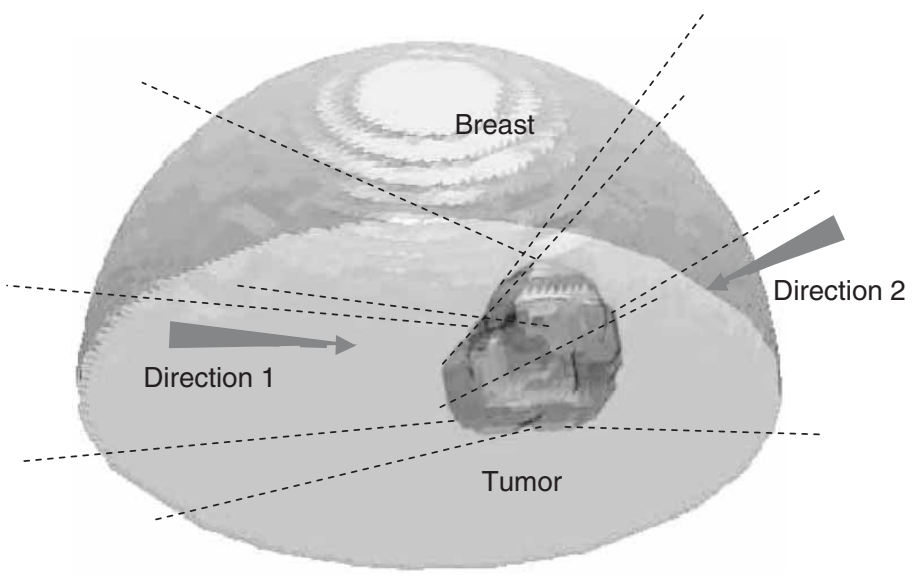

(a)

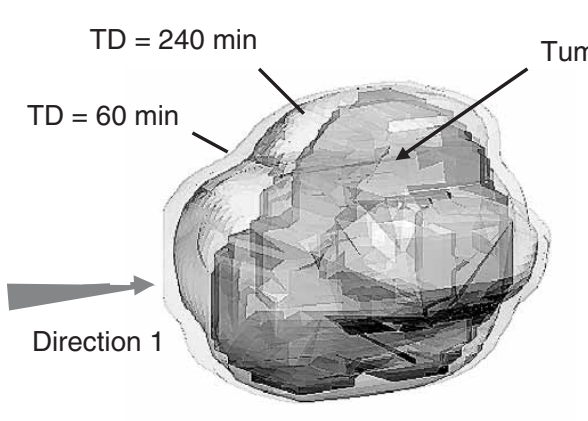

(b)

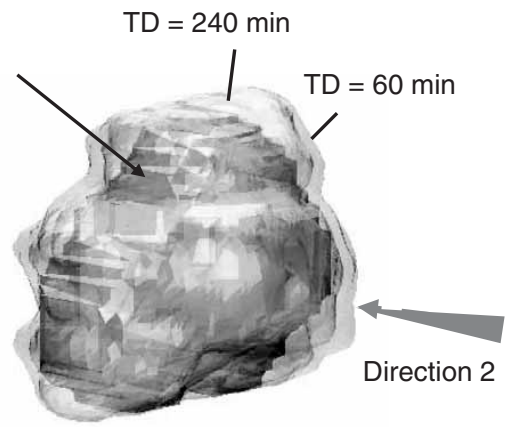

(c)

Figure 8. One practical treatment case of an irregular tumor located in female breast: (a) geometrical relation between breast and tumor; (b) and (c) surface views of PTV (pointed out by arrows) and TD $=60$ and 240 min iso-surfaces (pointed out by lines) after treatment while using two different power incident directions. Arrows indicate the incident direction of the ultrasonic energy.

dissipation in high blood perfusion condition (data not shown), and this led to the total treatment time to be shorter than the low blood perfusion case ( $31.5 \mathrm{~min}$ can be shortened to be $27.3 \mathrm{~min}$ ). Therefore, a dynamic cooling period determination algorithm (such as our previous proposed scheme [17]) may be considered to further improve the treatment time when generating large thermal lesions.

\section{Influence of the element number in ultrasound $2 D$ phased array}

Ultrasound 2D phased array is advantageous in its ability to generate multiple foci patterns while the foci can be generated off the central axis. However, the sidelobes became more apparent when the number of foci increases or the element number in the $2 \mathrm{D}$ phased array reduced $[10,38]$. Also the shifting distance of foci off main-axis of phased array depends on its element number. According to Fan and Hynynen [38], the axial shifting ability when the element number was larger than $16 \times 16$, can be extended to $4 \mathrm{~cm}$, and the suggested simultaneous focal number is $4-8$. As the element number was reduced to $4 \times 4$, the axial shifting ability was reduced to shorter than $2 \mathrm{~cm}$, and the suggested simultaneous focal number should not exceed four. For 2D phased arrays with fewer elements, it could be difficult to alter the depth or lateral shifting distance of the ultrasonic foci to cover a given region, and the proposed strategy may not be able to be applied due to the severer side-lobe generation. Other element dicing design includes the sectorvortex combined annular diced spherical phased array [39] and sparse, randomized distributed spherical phased array [40] compared with the squared dicing phased array used in this study. The multiple focal pattern generation among different diced phased array varied, however, same analysis can be made in other phased array types in the determination of element number.

\section{Effect of the transducer orientation}

In Table I and Figure 6, we have shown that the selection of the sonication orientation can considerably affect the treatment times and conformabilities. By selecting specific transducer orientation based on the tumor morphology and shape (in the proposed 
irregular case, the transducer orientation were set to its transducer axial direction parallel to tumor's long direction rather than the short direction), treatment times can be reduced by about $38 \%$, while the treatment conformability can be improved (EI can be reduced from 96.2 to $33.8 \%$ when keeping $\mathrm{CI}=100 \%$ ). A rule of thumb to perform a better transducer orientation selection can be explained in two aspects. First, a heating unit as large as possible should be used to reduce the number of the employed intervening cooling period between consecutive single sonications. Hence, aligning the transducer's axis parallel to the tumor's long axis can increase the possibility to thermally ablate larger subtarget regions in single sonication. Second, comparing with single focal-depth scanning, multiple focal-depth scanning scheme used to synthesize the heating patterns provides higher flexibility in forming a desired ablated volume along the axial direction. This can be easily examined by observing the TD distribution of the single focal depth scanning pattern (Figure 4a) and the multiple focal depth scanning patterns (Figure $4 \mathrm{~b}$ and c). Hence, while treating the tumor with less limited acoustic window such as the breast tumor, the transducer orientation should be optimally determined based on prior information from the treatment planning if there is no limitation for patient orientation on the treatment console; on the other hand, for treatment portion with limited acoustic window such as the uterine fibroid, the selection of the transducer becomes less feasible. Additionally, the usage of larger single heating unit by extending the size along the cross-sectional direction may become options to further shorten the total treatment time.

\section{Conformability evaluation by using CI and EI index}

In this study, we employed $\mathrm{CI}$ and $\mathrm{EI}_{\text {threshold }}$ index to quantify the treatment evaluation to emphasize on treatment conformability, where the concept was originated from radiation therapy and has been considered in ultrasound hyperthermia optimization $[41,42]$. Although these indexes used in ultrasound thermal therapy describes similar "dose conformability", it is important to note that the conceptual difference between "radiation dose" and "TD". Rather than a physical quantity measured such as energy absorption in defining radiation dose, TD is based on the analysis of Arrhenius relationship and is strongly dependent on its tissue type been heated, which implies that a thermal threshold for damage assessed may very from one tissue type to another [43]. Most of current optimization studies in ultrasound thermal therapy employed $\mathrm{TD}=240 \mathrm{~min}$ isodose distribution as a conservative threshold for complete destruction among various tissue types (equivalents to our CI concept). However, since $\mathrm{TD}=50-60 \mathrm{~min}$ has been reported to be sufficient for complete tissue necrosis in some cases $[43,44]$. The threshold of $\mathrm{CI}$ and $\mathrm{EI}_{\text {threshold }}$ should be therefore carefully selected based on the consideration of specific treatment portion or the surrounding important organ distribution.

The conformability criteria in ultrasound thermal therapy study may also be varied when using in various analysis. For example, in this study, CI value was enforced to be $100 \%$ regardless of the increase of $\mathrm{EI}_{\text {threshold }}$. This criterion may only be reasonable for target regions not surrounded by any important organ/tissue. Different criteria such as to minimize the difference between $\mathrm{CI}$ and EI (i.e., $\left.\min \left(\mathrm{CI}-\mathrm{EI}_{\text {threshold }}\right)\right)$ or only minimize $\mathrm{EI}_{\text {threshold }}$ regardless CI should be designed for specific optimization analysis.

\section{Conclusions}

In this study, we proposed a procedure to implement multiple focal-depth scanning and sequential heating into $2 \mathrm{D}$ phased array heating system, and some important factors of this heating strategy were investigated. The simulation results show that this heating procedure was feasible to shorten the treatment time and at the same time to increase the heating conformability, which are both significant issues in ultrasound thermal therapy. This study offers useful information for large-tumor thermal therapy with 256 element ultrasound phased array.

\section{Acknowledgments}

This work was supported in part by the National Science Council, Taiwan under Grant \#94-2622-E182-008-CC3 and Chang-Gung Memorial Hospital, Taiwan, under Grant \#CMRPD34022.

\section{References}

1. Ter Haar G. Ultrasound focal beam surgery. Ultrasound Med Biol 1995;21:1089-1100.

2. Visioli AG, Rivens IH, ter Haar GR, Horwich A, Huddart RA, Moshovic E, Padhani A, Gleese J. Preliminary results of a phase I dose escalation clinical trial using focused ultrasound in the treatment of localised tumours. Eur J Ultrasound 1999;9:11-8.

3. Stewart EA, Gedroyc WM, Tempany CM, Quade BJ, Inbar Y, Ehrenstein T, Shushan A, Hindley JT, Goldin RD, David M. Focused ultrasound treatment of uterine fibroid tumors: Safety and feasibility of a noninvasive thermoablative technique. Am J Obstet Gynecol 2003;189:48-54.

4. Tempany CM, Stewart EA, McDannold N, Quade BJ, Jolesz FA, Hynynen K. MR imaging-guided focused ultrasound surgery of uterine leiomyomas: A feasibility study. Radiology 2003;226:897-905. 
5. Hynynen K, Pomeroy O, Smith DN, Huber PE, McDannold NJ, Kettenbach J, Baum J, Singer S, Jolesz FA. MR imagingguided focused ultrasound surgery of fibroadenomas in the breast: A feasibility study. Radiology 2001;219:176-185.

6. Jolesz FA, Hynynen K. Magnetic resonance image-guided focused ultrasound surgery. Cancer J 2002;8(Suppl 1): S100-12.

7. O'Neil HT. Theory of focusing radiators. J Acoust Soc Am 1949;21:516-526.

8. Fan X, Hynynen K. Ultrasound surgery using multiple sonications - treatment time considerations. Ultrasound Med Biol 1996;22:471-482.

9. McGough RJ, Kessler ML, Ebbini ES, Cain CA. Treatment planning for hyperthermia with ultrasound phased arrays. IEEE Trans Ultrason Ferroelect Freq Contr 1996;43: 1074-1084

10. Fan X, Hynynen K. A study of various parameters of spherically curved phased arrays for noninvasive ultrasound surgery. Phys Med Biol 1996;41:591-608.

11. Hutchinson EB, Buchanan MT, Hynynen K. Design and optimization of an aperiodic ultrasound phased array for intracavitary prostate thermal therapies. Med Phys 1996;23:767-776.

12. Wan H, VanBaren P, Ebbini ES, Cain CA. Ultrasound surgery: Comparison of strategies using phased array systems. IEEE Trans Ultrason Ferroelect Freq Contr 1996;43: $1085-1098$.

13. Wu X, Sherar M. Theoretical evaluation of moderately focused spherical transducers and multi-focus acoustic lens/ transducer systems for ultrasound thermal therapy. Phys Med Biol 2002;47:1603-1621.

14. Daum DR, Hynynen K. A 256-element ultrasonic phased array system for the treatment of larger volumes of deep seated tissue. IEEE Trans Ultrason Ferroelec Freq Contr 1999;46:1254-1268.

15. Mougenot C, Salomir R, Palussiere J, Grenier N, Moonen $\mathrm{CT}$. Automatic spatial and temporal temperature control for MR-guided focused ultrasound using fast 3D MR thermometry and multispiral trajectory of the focal point. Magn Reson Med 2004;52:1005-15.

16. Malinen M, Huttunen T, Kaipio JP, Hynynen K. Scanning path optimization for ultrasound surgery. Phys Med Biol 2005;50:3473-3490.

17. Lin WL, Liang TC, Yen JY, Liu HL, Chen YY. Optimization of power deposition and a heating strategy for external ultrasound thermal therapy. Med Phys 2001;28:2172-2181.

18. Daum DR, Smith NB, King R, Hynynen K. In vivo demonstration of noninvasive thermal surgery of the liver and kidney using an ultrasonic phased array. Ultrasound Med Biol 1999;25:1087-1098.

19. Ebbini ES, Cain CA. A spherical-section ultrasound phased array applicator for deep localized hyperthermia. IEEE Trans Biomed Eng 1991;38:634-643.

20. Damianou C, Hynynen K. Focal spacing and near-field heating during pulsed high temperature ultrasound therapy. Ultrasound Med Biol 1993;19:777-787.

21. Relkaitis GA, Ravindran A, Ragsdell KM. Engineering optimization: Methods adn applications. New York: Wiley; 1983.

22. Sibille A, Prat F, Chapelon JY, Abou el Fadil F, Henry L, Theillere Y, Panchon T, Cathignol D. Extracorporeal ablation of liver tissue by high-intensity focused ultrasound. Oncology 1993;50:375-379.

23. Hynynen $\mathrm{K}$. The threshold for thermally significant cavitation in dog's thigh muscle in vivo. Ultrasound Med Biol 1991;17:157-169.

24. Liu HL, Chen YY, Yen JY, Lin WL. Treatment time reduction for large thermal lesions by using a multiple 1D ultrasound phased array system. Phys Med Biol 2003;48:1173-1190.

25. Dewey WC. Arrhenius relationships from the molecule and cell to the clinic. Int J Hyperthermia 1994;10:457-483.

26. Sapareto SA, Dewey WC. Thermal dose determination in cancer therapy. Int $\mathrm{J}$ Radiat Oncol Biol Phys 1984;10:787-800.

27. Pearce J, Thomsen S. Rate process analysis of thermal damage. In: Welch AJ and van Gemert MJC, editors. Optical-thermal resopnse of laser-irradiated tissue. New York: Plenum; 1995.

28. Damianou C, Hynynen K. The effect of various physical parameters on the size and shape of necrosed tissue volume during ultrasound surgery. $\mathrm{J}$ Acoust Soc Am 1994;95:1641-1649.

29. Pennes HH. Analysis of tissue and arterial blood temperatures in the resting human forearm. J Appl Physiol $1948 ; 1: 193-222$.

30. Kolios MC, Sherar MD, Hunt JW. Temperature dependent tissue properties and ultrasonic lesion formation. In: Scott E, editor. Advances in heat and mass transfer in biotechnology. New York: ASME; 1999. pp 113-118.

31. Mahoney K, Fiield T, McDannold N, Clement G, Hynynen $\mathrm{K}$. Comparison of modelled and observed in vivo temperature elevations induced by focused ultrasound: Implications for treatment planning. Phys Med Biol 2001;46:1785-1798.

32. Connor CW, Hynynen K. Bio-acoustic thermal lensing and nonlinear propagation in focused ultrasound surgery using large focal spots: A parametric study. Phys Med Biol 2002;47:1911-1928.

33. Liu HL, McDannold N, Hynynen K. Focal beam distortion and treatment planning in abdominal focused ultrasound surgery. Med Phys 2005;32:1270-1280.

34. Arditi M, Foster FS, Hunt JW. Transient fields of concave annular arrays. Ultrason Imaging 1981;3:37-61.

35. Damianou CA, Sanghvi NT, Fry FJ, Maass-Moreno R. Dependence of ultrasonic attenuation and absorption in dog soft tissues on temperature and thermal dose. J Acoust Soc Am 1997;102:628-634.

36. Gertner MR, Wilson BC, Sherar MD. Ultrasound properties of liver tissue during heating. Ultrasound Med Biol 1997;23:1395-1403.

37. Leibel SA, Phillips TL. Textbook of radiation oncology. Philadelphia: Saunders; 2004.

38. Fan X, Hynynen K. Control of the necrosed tissue volume during noninvasive ultrasound surgery using a 16-element phased array. Med Phys 1995;22:297-306.

39. Fjield T, Sorrentino V, Cline H, Hynynen K. Design and experimental verification of thin acoustic lenses for the coagulation of large tissue volumes. Phys Med Biol 1997;42:2341-2354.

40. Pernot M, Aubry JF, Tanter M, Thomas JL, Fink M. High power transcranial beam steering for ultrasonic brain therapy. Phys Med Biol 2003;48:2577-2589.

41. Diederich CJ, Hynynen K. Ultrasound technology for hyperthermia. Ultrasound Med Biol 1999;25:871-887.

42. Ju KC, Chen YY, Lin WL, Kuo TS. One-dimensional phased array with mechanical motion for conformal ultrasound hyperthermia. Phys Med Biol 2003;48:167-182.

43. Dewhirst MW, Viglianti BL, Lora-Michiels M, Hanson M, Hoopes PJ. Basic principles of thermal dosimetry and thermal thresholds for tissue damage from hyperthermia. Int $\mathrm{J}$ Hyperthermia 2003;19:267-294.

44. McDannold N, King RL, Jolesz FA, Hynynen K. The use of quantitative temperature images to predict the optimal power for focused ultrasound surgery: In vivo verification in rabbit muscle and brain. Med Phys 2002;29:356-365. 
Copyright of International Journal of Hyperthermia is the property of Taylor \& Francis Ltd and its content may not be copied or emailed to multiple sites or posted to a listserv without the copyright holder's express written permission. However, users may print, download, or email articles for individual use. 
Copyright of International Journal of Hyperthermia is the property of Taylor \& Francis Ltd and its content may not be copied or emailed to multiple sites or posted to a listserv without the copyright holder's express written permission. However, users may print, download, or email articles for individual use. 